\title{
A Substrain Mouse Serologically Classified in ddN Strain and Its Behavioral Gharacteristics
}

\author{
Nobuhiko Furuya* and Takehisa Hirao \\ Departent of Behavior and Physiology, Behavior Research \\ Institute, University of Gunma Medical School, Maebashi
}

Furuya, N. and Hirao, T. A Substrain Mouse Serologically Classified in ddN Strain and Its Behavioral Characteristics. Tohoku J. exp. Med., 1976, 118 (4), 355-363 — A special substrain mouse in ddN strain was classified by cross agglutination reaction of the red blood cells with anti-ddN mice red blood cells rabbit immune serum. The agglutination reactivity in the full-grown substrain mouse was as high as in an infant ddN mouse. Incidence of the substrain mouse in ddN strain aged older than 9 weeks was about $10 \%$. The full-grown substrain mouse revealed a form of excitation after long-term administration of methamphetamine while other mice in the same strain were depressed. The behavioral and serological properties of histocompatible strain mice such as $\mathrm{C}_{5} \mathrm{Bl}$ and $\mathrm{C}_{3} \mathrm{H}$ were studied to compare with those of the ddN substrain mouse. —_ serology, behavior; ddN mouse; methamphetamine

Disordered behavior due to long-term administration of methamphetamine was studied in ddN strain mouse by Utena and Takano (1960). They found a long-lasting reduction of motor activity in revolving activity wheel. Utena (1966) took this behavior for the "manifestation of a loss of spontaneity". We studied the positional behavior in the $\mathrm{ddN}$ mice with and without methamphetamine treatment by a new technique named "cloister method" (Hirao and Utena 1962; Hirao et al. 1973, 1975), and found that some of them revealed a special behavioral characteristic of excitation. It has been reported that the behavioral changes in mice produced by the administration of amphetamine are strain-dependent (Weaver and Kerley 1962; Brown 1965; Randrup and Munkvad 1967). We attempted to classify the mouse genetically by serological reaction of blood, and fortuitously found a special substrain mouse whose red blood cells proved an infant type of agglutination to a special antiserum prepared, this substrain mouse demonstrated the form of excitation subsequent to the long-term administration of methamphetamine, whereas the other ddN mice which showed serologically a form of maturity revealed depressed behavior. These different types of disordered behavior manifested in the same strain mouse depended on the genetical marker.

This report deals with the blood serological reactivity by which the substrain was classified, and with the behavioral characteristic of the substrain mouse comparing with those of the other strains of mice.

Received for publication, November 18, 1975.

* Present address: Department of Otorhinolaryngology, University of Tokyo Medical School, Tokyo. 


\section{Materials and Methods}

\section{Experimental animals}

Male mice of 3 strains ddN, $\mathrm{C}_{57} \mathrm{Bl}$ and $\mathrm{C}_{3} \mathrm{H}$ were used. They were housed in groups of 10 in each cage $\left(30 \times 20 \times 15 \mathrm{~cm}^{3}\right)$, in a sound-proof room with constant temperature $\left(22 \pm 2^{\circ} \mathrm{C}\right)$ and controlled illumination (on at 9 a.m., off at 9 p.m.).

\section{Serological study}

(a) Immunization of rabbit by the ddN mice red blood cells

Blood of full-grown ddN mice was collected by heart puncture under ether anesthesia, and was washed with physiological saline. Leucocytes were removed, and a $20 \%$ suspension of red blood cells in physiological saline was prepared. The suspension was injected into the periauricular vein of a rabbit repeatedly, i.e., on every third day, each time increasing its quantity from the initial dose of $0.5 \mathrm{ml}$ by $0.5 \mathrm{ml}$ steps. The process of immunization was checked after 3 weeks on the agglutinine titer of the serum sampled from the rabbit blood. The procedure was performed until the titer was sufficiently high (1:5000 or over), and the animal was bled from the carotid artery under ether anesthesia. The serum was separated from the blood, heated at $56^{\circ} \mathrm{C}$ for $30 \mathrm{~min}$, and filtered.

(b) "Mo+" and "Mo-" type red blood cells

In order to examine cross agglutination reactivity of ddN mice red blood cells with the serum, the species-specific antibody was absorbed separately by the blood cells of each mouse.

The serum of $0.025 \mathrm{ml}$ each was diluted 10 -fold with saline and mixed with $0.25 \mathrm{ml}$ of washed red blood cells of a ddN mouse. The mixture was kept in a refrigerator for $30 \mathrm{~min}$, then kept at $24^{\circ} \mathrm{C}$ for $2 \mathrm{hr}$ and the supernatant was collected. The absorption was repeated two or three times until agglutination of the blood cells disappeared. The red blood cells of each mouse whose blood was used separately for the absorption were mutually examined for cross agglutination reactivity with those absorbed sera. The absorbed sera which still showed high titer ( $>256$-fold) of agglutinine to a special mouse blood cells were obtained, by which new mice were tested for the blood reactivity in each (see below in (c)), and two groups of ddN mice could be classified; mice older than 6 weeks and whose red blood cells showed the high agglutination reactivity, and mice younger than 5 weeks and whose blood cells lost the reactivity.

A new rabbit was immunized with red blood cells of the mouse in the former group by the same procedure as described previously. After completing the schedule of immunization, the rabbit's serum was collected and named "anti-Mo+ rabbit serum" and was treated at $56^{\circ} \mathrm{C}$ with $0.1 \%$ sodium azide for $30 \mathrm{~min}$, lyophilized, and stored in a refrigerator. When it was used, after dilution, the species-specific antibody was absorbed by red blood cells of the mouse in the latter group. This absorbed serum was named "anti-Mo+ serum".

(c) Agglutination test of individual mouse blood cells

Under ether anesthesia, blood was collected from the tail by snipping off the tip, and washed with physiological saline. Two \% suspension of the red blood cells was prepared and the agglutination reaction to the anti-Mo+ serum was tested. The red blood cells which positively reacted (1:60 or over) were named "Mo+" type and the negative ones "Mo - " type, and these mice were called "Mo + mouse" and "Mo- mouse" respectively.

The mouse whose red blood cells showed the Mo- type before 5 weeks of age was named "Mo I mouse" and was kept separately to be used its blood specially for the absorption of the species-specific antibody in the anti-Mo+ rabbit serum.

Each mouse subjected to the behavioral experiment was serologically checked at 4 and 7 weeks of age, and again after completion of the cloister experiment. 


\section{Administration of methamphetamine}

Methamphetamine- $\mathrm{HCl}$ was dissolved in physiological saline and injected subcutaneously (0.2 ml per mouse).

In the case of long-term administration, the mouse aged 4 weeks was subjected to daily subcutaneous injection of methamphetamine- $\mathrm{HCl}(2 \mathrm{mg} / \mathrm{kg}$ of body weight) for 4 weeks. Four days after completion of the chronic administration, i.e., after disappearance of the drug from body, the mouse was put into the clositer (see below) for one or two months.

\section{Behavioral study}

An analysis was performed on the positional behavior of a mouse living individually inside a circular corridor-like cage named "cloister", this enclosure was composed of 20 cubicles whose volume was $7 \times 10 \times 10 \mathrm{~cm}^{3}$ (Fig. 1). Position of the mouse was electrically detected and recorded by an 8 bit paper-tape punch. The mouse aged 9 weeks was placed into the cloister.

Locomotive activity was determined by the number of cubicles moved by the mouse in a given time.

Each distance moved by the mouse per movement bout was measured until the mouse was regarded as having stopped, i.e., it stayed at a cubicle for more than 1.5 sec. The locomotive activity was sum of each distance of the movement bout observed in the same period, and number of the movement bouts was measured. The criterion interval of 1.5 sec was determined so that the distance may follow the probability law of geometric distribution (Hirao et al. 1971, 1975).

An initial change of daily locomotive activity showed a process of the subject's adapta-

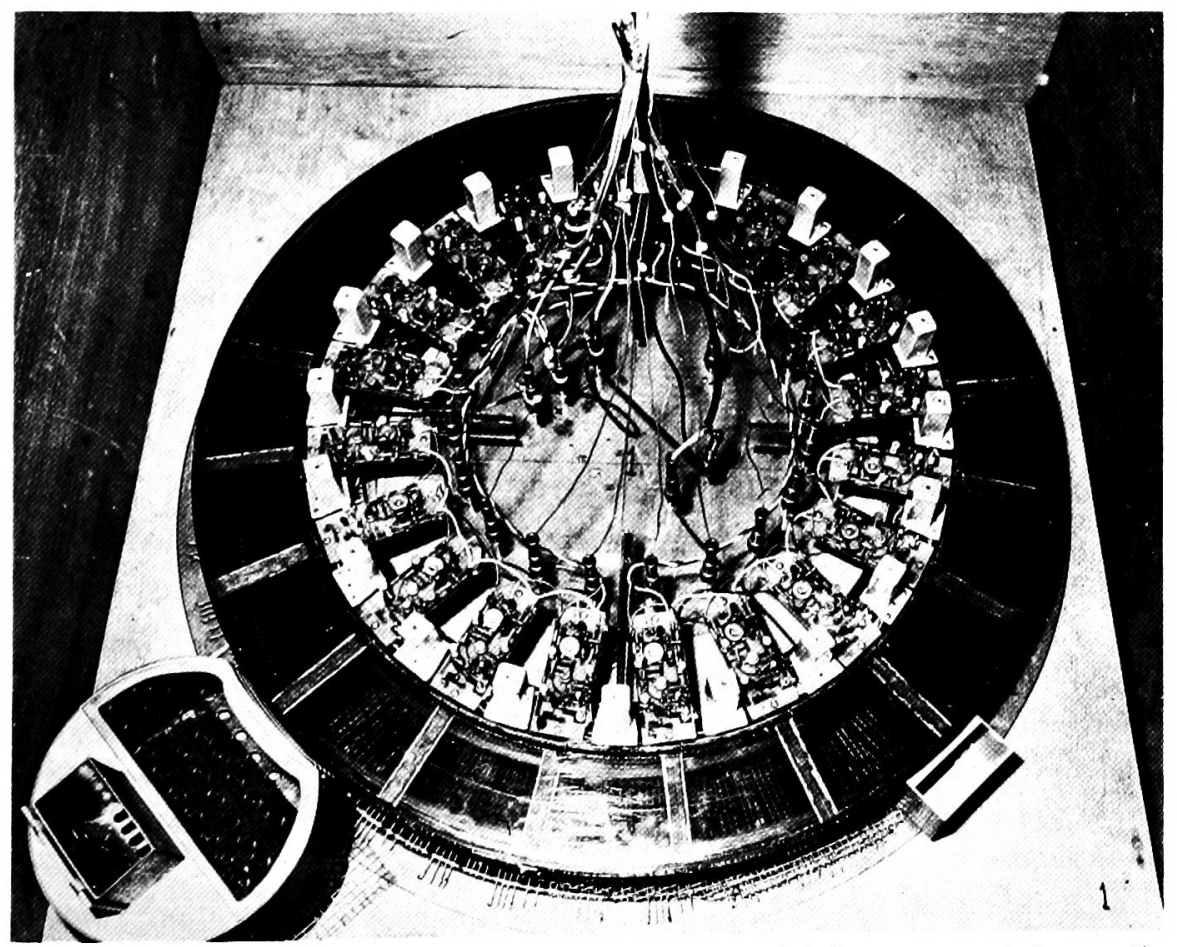

Fig. 1. Cloister with 20 cubicles. A small cage set in the left lower corner is for another mouse which visually stimulates the subjected mouse. 
tion to new surrounding, the value decreased to a stable level with some fluctuation in 3 weeks. Behavior of each mouse was compared in this adapted state, when the mouse was older than 12 weeks.

\section{Results}

\section{Serological study}

Incidence of the Mo+ mouse was checked in each group of 100 mice of the same age. In the ddN strain, it was $100 \%$ between 1 and 3 weeks of age, diminished to $70 \%$ at 4 weeks old, and reached a stable level of about $10 \%$ when the mouse was 7 weeks old (Fig. 2). And 10\% of the full-grown ddN strain mice serologically remained in the infant state. The purely inbred strains, such as $\mathrm{C}_{57} \mathrm{Bl}$ and $\mathrm{C}_{3} \mathrm{H}$, showed a similar but earlier loss of the Mo+ type than did ddN strain mcie. The incidence started from $100 \%$ at 1 week old, decreased to $40 \%$ at 3 weeks old in $\mathrm{C}_{3} \mathrm{H}$ and 4 weeks old in $\mathrm{C}_{57} \mathrm{Bl}$, and disappeared when the mouse was 7 weeks old in $\mathrm{C}_{3} \mathrm{H}$ and 9 weeks old in $\mathrm{C}_{57} \mathrm{Bl}$. The $\mathrm{Mo}+$ mouse was not found in the full-grown $\mathrm{C}_{57} \mathrm{Bl}$ and $\mathrm{C}_{3} \mathrm{H}$ strains.

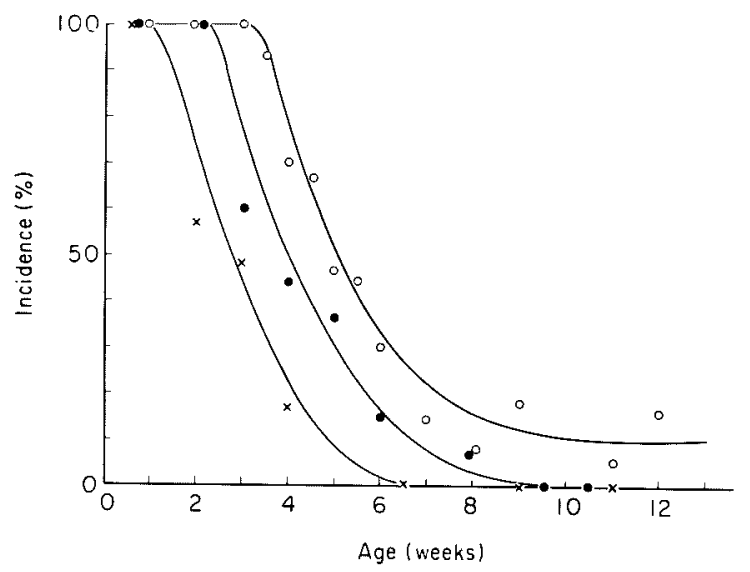

Fig. 2. Incidences of the Mo+ mouse in the male mouse of $\operatorname{ddN}(0), \mathrm{C}_{57} \mathrm{Bl}(\bullet)$, and $\mathrm{C}_{3} \mathrm{H}$ $(x)$ strains. The abscissa presents the mouse age.

To study the changing process of agglutination reactivity in red blood cells, from $\mathrm{Mo}+$ to Mo-type, the titer of blood cells was followed up in each individual $\mathrm{ddN}$ mouse in two series of checking periods at the ages of 3,6 and 8 weeks and of 2, 5 and 7 weeks. The titer before turning to the Mo-type was not significantly related to the maintenace of Mo+ reactivity, and the Mo- mouse never reverted to $\mathrm{Mo}+$ mouse.

The Mo+ mouse whose blood cells maintained high agglutination reactivity to the anti-Mo+ serum after behavioral experiment (at about 17 weeks old) was named "Mo II substrain mouse" or simply "Mo II mouse". 
We separately kept 3 groups of the ddN strain mouse; the Mo I mouse, the Mo II mouse, and the mouse whose blood changed to Mo- type over 5 weeks of age. Incidence of the full-grown Mo I mouse was about $50 \%$ in the ddN strain, which was regarded as being matured early and was subjected for behavioral experiment as an extreme type of matured ddN strain against the Mo II mouse. All kept in the group of Mo II mouse were older than 4 months, some of them were older than 20 months, and the agglutination titer of their red blood cells remained in the infant high level.

We also checked the female Mo II mouse in ddN strain and found the similar incidence with that in the male mouse, inbreeding experiments of Mo II substrain were not successful because the lines died out after 2 or 3 generations.

"Anti-Mo- serum" was also prepared by red blood cells of the Mo I mouse being absorbed with the Mo+ type red blood cells, but its agglutinine titer to the Mo - tpye red blood cells could not be brought up to the high level, although this attempt was repeated changing the host ainimal to the domestic cock. Thus, it was considered that the Mo- reactivity was species-specific of the mouse red blood cells, and that the Mo+ reactivity showed a genetical marker of the peculiar substrain which revealed a form of immaturity.

\section{Behavioral study}

Double peaked circadian rhythm of the locomotive activity was observed in full-grown ddN strain mouse, and monophasic circadian rhythm was shown by the full-grown $\mathrm{C}_{57} \mathrm{Bl}$ and $\mathrm{C}_{3} \mathrm{H}$ strains mice (Fig. 3).

The number of movement bouts per hr also revealed the double peaked circadian rhythm in the Mo I mouse, and the monophasic rhythm in the Mo II substrain mouse (Fig. 4). No mice demonstrated the monophasic rhythm in the locomotive activity with the double peaked rhythm in the number of movement bouts.

Subsequent to the long-term administration of methamphetamine these circadian rhythms were disturbed.

Daily locomotive activity in each strain mouse was not significantly different from others but reduced after the long-term administration of methamphetamine; this reduction was due to the decreased number of movement bouts but not to the distance of movement bout. In the Mo II mouse, however, the long-term treatment increased more than twice the distance of movement bout (Fig. 5).*

An acute response to the administration of methamphetamine $(>0.5 \mathrm{mg} / \mathrm{kg})$ was commonly observed as a augmented locomotive activity due to the increased number of movement bouts in all the mice, in the Mo II mouse the distance of movement bout was readily doubled and its locomotive activity increased to the

* The distance of movement bont should follow the probability law of geometric distribution insofar as the minimum staying time was determined $1.5 \mathrm{sec}$ in this cloister method (Hirao et al. 1971), and the population mean was 2 . Thus, the probability that the mean in a large sample was more than 4 was estimated less than $0.1 \%$. 


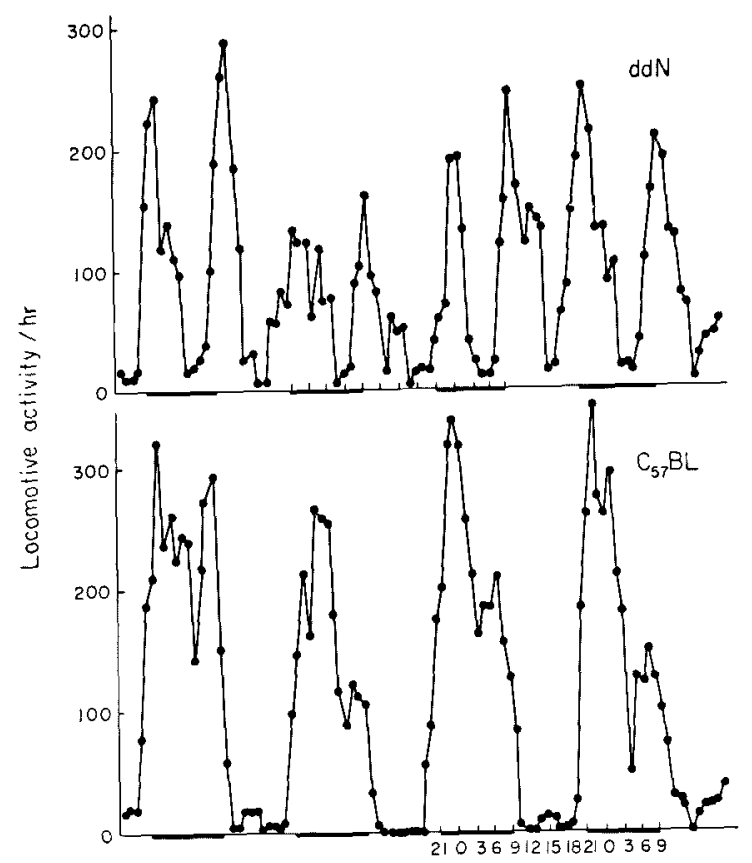

Fig. 3. Circadian rhythm of the locomotive activity per hr. The upper curve is that of a ddN strain mouse, and the lower is that of a $\mathrm{C}_{57} \mathrm{Bl}$ strain mouse. The abscissa presents time shown by $\mathrm{hr}$ and the bold part signifies night time.

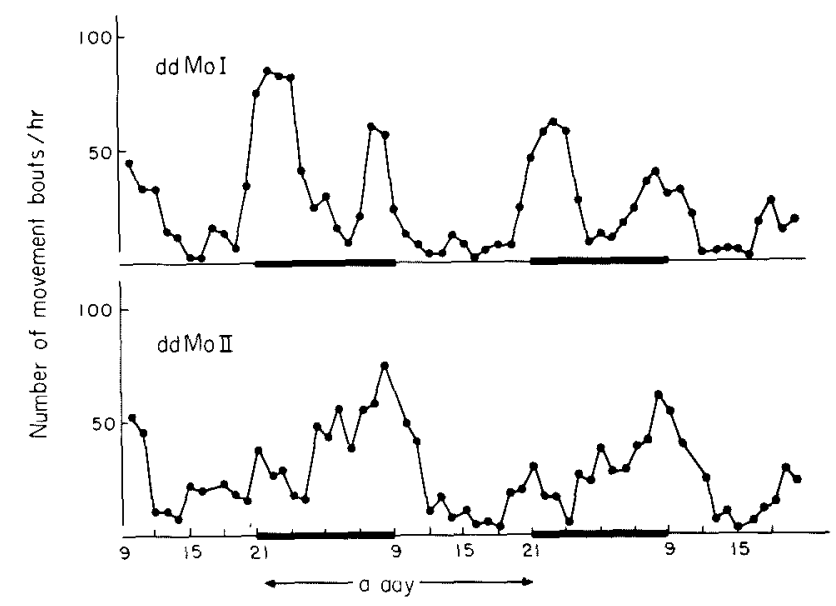

Fig. 4. Circadian rhythm of the number of movement bouts per hr. The upper curve is that of the Mo I mouse and the lower is that of the Mo II mouse.

high level as shown in the chronically treated Mo II mouse (Fig. 6), but the Mo I mouse kept the ordinary level of distance of movement bout unless the dosage was more than $2 \mathrm{mg} / \mathrm{kg}$. The change of the distance was not proved in $\mathrm{C}_{57} \mathrm{Bl}$ and $\mathrm{C}_{3} \mathrm{H}$ strains mice. 


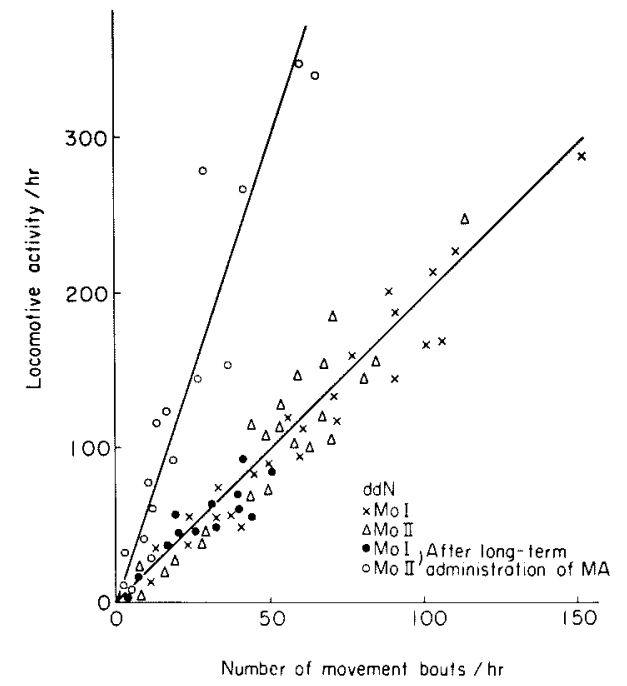

Fig. 5. Relation between the locomotive activity and the number of movement bouts measured per hr. Different kinds of mark were plotted corresponding with mice illustrated on the figure. Different inclinations are shown by the two lines, which estimate sample mean of the distance of movement bout.

Occasionally the Mo+ mouse which was treated with long-term administration of methamphetamine decreased the distance of movement bout during the behavioral experiment from the level of Mo II mouse to that of Mo I mouse, in this case the blood reactivity also changed to the Mo- type (Fig. 7). And the typical behavioral characteristics of the Mo II mouse were defined as those of the mouse whose red blood cells showed the Mo+ type after the behavior experiment.

\section{Discussion}

The double peaked circadian rhythm of locomotive activity in the $\mathrm{ddN}$ strain mouse might reveal its specially sensitive activity to on- and off-stimuli of the illumination as compared with the other strains of mice which showed monophasic nocturnal rhythm. It has been reported that the ddN strain mouse demonstrated special disordered behavior by the administration of methamphetamine but other strains such as $\mathrm{C}_{57} \mathrm{Bl}$ and $\mathrm{C}_{3} \mathrm{H}$ did not show it, and that was attributed to the special sensitivity of the $d d N$ strain mouse. The acute disordered activity produced by the administration of methamphetamine in the ddN strain mouse consisted of the increased distance and number of movement bout, and the former component was manifested in the Mo II substrain. Their movements were so sluggish and continuous that some experimenters have called "stereotyped and autistic" (Randrup and Munkvad 1967), or "aimless" (Ellinwood 1972).

Reduction of the number of movement bouts was a general disordered characteristic subsequent to the long-term administration of methamphetamine, but the distance was maintained at ordinary level in the Mo I mouse and was doubled in 


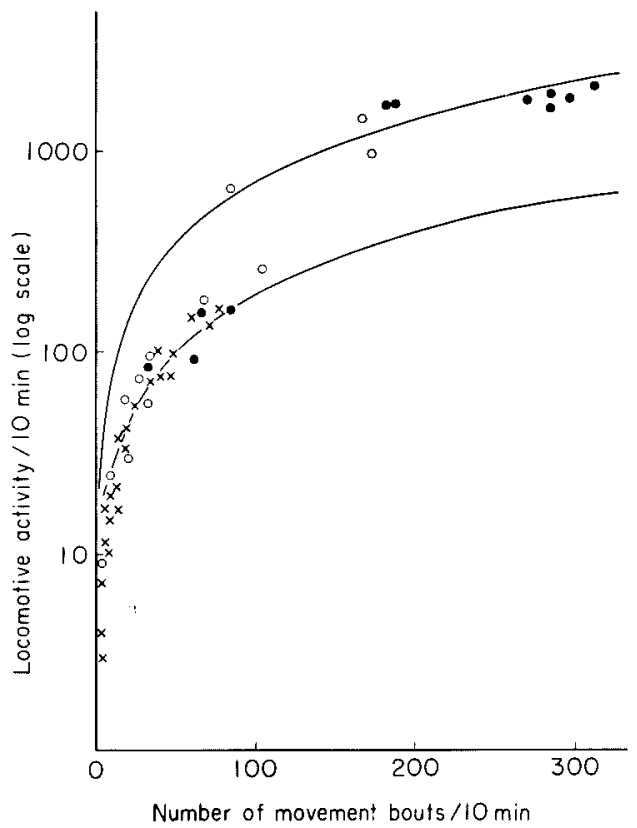

Fig. 6. Acute change of behavioral characteristic of the Mo I mouse to the methamphetamine administration. Two smooth curves correspond with the two lines shown in Fig. 5. The difference in shape is due to the logarithmic scale of the ordinate, needed to fit on the full range of data. In the case of this picture, the symbols illustrate the response of a Mo I mouse to $2.5 \mathrm{mg} / \mathrm{kg}$ methamphetamine- $\mathrm{HCl}$, and the behavioral activity was measured in each $10 \mathrm{~min}$. The mark (•) presents the values observed between just after the injection and $2 \mathrm{hr}$ passed, the mark (o) between 2 and $4 \mathrm{hr}$, and $(\nvdash)$ between 4 and $7 \mathrm{hr}$.
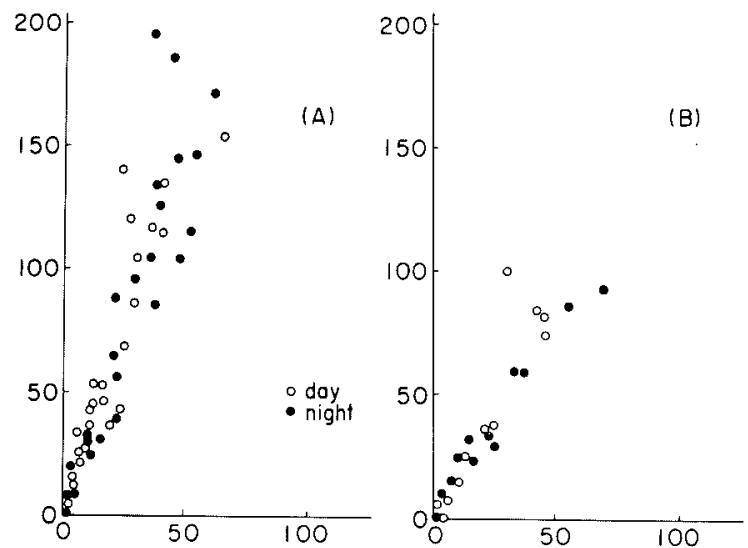

Fig. 7. In each figure, the ordinate presents the locomotive activity in $1 \mathrm{hr}$, and the abscissa the number of movement bouts. Fig. (A) shows those values observed in 2 days in the 9th week after housing in the cloister, and (B) shows those in a day in loth week when the inclination changes to that of the Mo I characteristic. 
the Mo II mouse. The reduction of motor activity produced by the same treatment in the ddN mouse was taken for the "loss of spontaneity" by Utena (1960) because of its maintenance of "normal velocity" in the turning wheel. In this sense, the doubled distance revealed by the Mo II mouse might be due to a loss of control of movement or a type of excitation.

Body weight and life-span of the Mo II mouse were not significantly different from those of the Mo I mouse, but the concomitant changes of both blood type and behavioral characteristic during behavioral experiment suggested that the $\mathrm{Mo}+$ reactivity was a genetical marker which showed the maintenance of a certain pattern of behavior in an immatured ddN substrain mouse, which may concern with the excited characteristic of the disordered behavior.

We may have to mention behaviors of the other Mo- mouse in the $d d \mathrm{~N}$ strain whose red blood cells converted to the Mo - type over 5 weeks of age and whose incidence was about $40 \%$ in the full-grown ddN mice. Its behavioral characteristics were intermediate between those of the Mo II and Mo I mouse, and depended upon the interval between the age of changing blood type and the date of behavior observation but were near to the latter one.

\section{Acknowledgment}

The authors are indebted to Emer. Prof. S. Izeki and Prof. S. Mitsuhashi for discussions about the serological experiment, and are also grateful to Prof. H. Utena for his discussion during the preparation of the manuscript.

\section{References}

1) Brown, A.M. (1965) Pharmacologenetics of the mouse. Lab. Animal Care, 15, 111118.

2) Ellinwood, E.H., Jr. (1972) Behavioral analysis of chronic amphetamine intoxication. Biol. Psychiat., 4, 215-230.

3) Hirao, T. \& Utena, H. (1962) New instrument to measure the directed movement of mouse. Protein, Nucleic Acid and Enzyme (Jap.), 7, 789.

4) Hirao, T., Furuya, N. \& Utena, H. (1971) Single pass. Brain and Nerve (Jap.), 15, 147-153.

5) Hirao, T., Shinozaki, H., Furuya, N. \& Ishikawa, M. (1973) A new behavior measuring system; cloister method. J. Physiol. Soc. Jap. (Jap.), 35 10-18.

6) Hirao, T., Shinozaki, H., Furuya, N. \& Ishikawa, M. (1975) An automatic recording system of the positional behavior of mice for experimental analysis. Behav. Res. Meth. Instr. 7, 267-272.

7) Randrup, A. \& Munkvad, I. (1967) Stereotyped activity produced by amphetamine in several animal species and man. Psychopharmacologia (Berl), 11, 300-310.

8) Utena, H. (1966) Behavioral aberrations in MA-intoxoicated animals. Progr. Brain Res, 213, 192-207.

9) Utena, H. \& Takano, S. (1960) Reduction of spontaneous activity of mice induced by drugs. Folia psychiat. neurol. jap., Suppl. 6, 38-47.

10) Weaver, L.C. \& Kerley, T.L. (1962) Strain difference in response of mice to Damphetamine. J. Pharmacol. exp. Ther., 135, 240-244. 